\title{
Formation of complex organic molecules in ice mantles: An ab initio molecular dynamics study
}

\author{
Natalia Inostroza ${ }^{1}$, Diego Mardones ${ }^{2,3}$, Jose Cernicharo ${ }^{4}$, Hans Zinnecker ${ }^{1}$, Jixing Ge$^{2}$, Nelson Aria ${ }^{5}$, \\ Patricio Fuentealba ${ }^{6,7}$, and Carlos Cardenas ${ }^{6,7}$ \\ 1 Universidad Autónoma de Chile, Facultad de Ingeniería, Núcleo de Astroquímica \& Astrofísica, Av. Pedro de Valdivia 425, \\ Providencia, Santiago, Chile \\ e-mail: natalia.inostroza@uautonoma.cl \\ 2 Universidad de Chile, Facultad de Ciencias Físicas y Matemáticas, Departamento de Astronomía, Camino el Observatorio 1515 , \\ Las Condes, Santiago, Chile \\ 3 Center for Astrochemical Studies, Max Planck Institute for Extraterrestial Physics, Giessenbachstrasse 1, \\ 85748 Garching, Germany \\ 4 Consejo Superior de Investigaciones Cientificas CSIC-IFF, Serrano 121, Madrid, Spain \\ 5 Universidad Andrés Bello, Doctorado en Fisicoquímica Molecular, República 275, Santiago, Chile \\ 6 Universidad de Chile, Facultad de Ciencias, Departamento de Física, Av. Las Palmeras 3425, Ñuñoa, Santiago, Chile \\ 7 Centro para el Desarrollo de la Nanociencia y la Nanotecnología (CEDENNA), Avda. Ecuador 3493, Santiago 9170124, Chile
}

Received 6 August 2018 / Accepted 10 July 2019

\begin{abstract}
We present a detailed simulation of a dust grain covered by a decamer of $\left(\mathrm{CH}_{3} \mathrm{OH}\right)_{10}$-ice-mantle, bombarded by an $\mathrm{OH}^{-}$closed-shell molecule with kinetic energies from 10-22 eV. The chemical pathways are studied through Born-Oppenheimer (ab initio) molecular dynamics. The simulations show that methanol ice-mantles can be a key generator of complex organic molecules (COMs). We report the formation of COMs such as methylene glycol $\left(\mathrm{CH}_{2}(\mathrm{OH})_{2}\right)$ and the $\mathrm{OCH}_{2} \mathrm{OH}$ radical, which have not been detected yet in the interstellar medium (ISM). We discuss the chemical formation of new species through the reaction of $\mathrm{CH}_{3} \mathrm{OH}$ with the hydroxyl projectile. The dependence of the outcome on the kinetic energy of the projectile and the implications for the observation and detection of these molecules might explain why the methoxy radical $\left(\mathrm{CH}_{3} \cdot\right.$ ) has been observed in a wider range of astrophysical environments than the hydroxymethyl $\left(\mathrm{CH}_{2} \mathrm{OH} \cdot\right)$ isomer. Because of the projectile kinetic energies required for these reactions to occur, we suggest that these processes are likely relevant in the production of COMs in photodissociation and shock regions produced by high-velocity jets and outflows from young stellar objects.
\end{abstract}

Key words. astrochemistry - molecular processes - ISM: molecules - dust, extinction

\section{Introduction}

Methanol $\left(\mathrm{CH}_{3} \mathrm{OH}\right)$ is one of the most abundant organic molecules in interstellar clouds (e.g., Öberg et al. 2010) and has even been detected in extragalactic objects (e.g., Saito et al. $2015,2016)$. However, its formation in the gas phase is highly inefficient (Geppert et al. 2006). Observations with the Infrared Space Observatory (ISO) have shown methanol on ice layers of dust grains (Ehrenfreund \& Schutte 2000). This led to the proposal of formation mechanisms on the ice mantles of dust grains through hydrogenation of CO (see, e.g. Gibb et al. 2004 and references therein). It is assumed that collisions between molecules and dust grains in dense and cold regions of interstellar clouds lead to the deposition of gas-phase molecules on the grain surfaces, forming ice mantles (see, e.g. Zahorecz et al. 2017 and references therein). This initiates a rich chemistry that leads to the formation of complex organic molecules (COMs), including methanol.

Bacmann \& Faure (2016) studied eight star-forming regions with different physical and chemical conditions. They found a relationship between the abundances of species such as $\mathrm{HCO}$, $\mathrm{CH}_{3} \mathrm{O}^{\bullet}, \mathrm{H}_{2} \mathrm{CO}$, and $\mathrm{CH}_{3} \mathrm{OH}$. Formaldehyde $\left(\mathrm{H}_{2} \mathrm{CO}\right)$ was considered as a precursor of $\mathrm{CH}_{3} \mathrm{OH}$ (Bacmann \& Faure 2016) on the ices. Several laboratory experiments that were conducted to predict the formation of COMs using $\mathrm{CH}_{3} \mathrm{OH}$-rich ices with $\mathrm{UV}$ irradiation have been performed (e.g., Öberg et al. 2009). As a consequence of these experiments, a detailed chemical network has been established to explain the formation of COMs such as dimethyl ether on the ices. In addition to the ice chemistry, several reactions in the gas phase could lead to the formation of COMs. For example, Harada et al. (2017) have found that dimethyl ether $\mathrm{CH}_{3} \mathrm{OCH}_{3}$ can be produced in the gas phase at times shorter than $5 \times 10^{4} \mathrm{yr}$, while grain surface processes dominate for longer times. Gas-phase processes such as radiative associations have also been proposed to produce COMs from small radicals such as $\mathrm{CH}_{3} \mathrm{O}$ and $\mathrm{CH}_{3}$ (Balucani et al. 2015).

The discovery of COMs in cold dark clouds such as methyl formate, dimethyl ether (Cernicharo et al. 2012; see also Öberg et al. 2010; Bacmann et al. 2012), and methanol (Coutens et al. 2017) represents a challenge for astrochemical models as desorption mechanisms from the ices are not very efficient in these cold objects, which, in addition, are well protected against UV radiation. As a consequence, the observed abundances of COMs in cold environments cannot be reproduced by current chemical models (Vasyunin et al. 2017). In this context, theoretical and modeling efforts have been 
made by Vasyunin \& Herbst (2013), Reboussin et al. (2014), Balucani et al. (2015), Chang \& Herbst (2016), and Ruaud et al. (2015) to study the formation and abundances of COMs. The abundances reported, for example, by Ruaud et al. (2015) in their gas-grain models underestimate the observed values in cold dense cores (e.g., B1-b and L1689b) by more than two orders of magnitude.

The observations of Cernicharo et al. (2012) toward the cold core B1-b show methyl mercaptan $\left(\mathrm{CH}_{3} \mathrm{SH}\right)$, methoxy $\left(\mathrm{CH}_{3} \mathrm{O}^{\bullet}\right)$, formic acid $(\mathrm{HCOOH})$, propynal $(\mathrm{HCCCHO})$, acetaldehyde $\left(\mathrm{CH}_{3} \mathrm{CHO}\right)$, dimethyl ether $\left(\mathrm{CH}_{3} \mathrm{OCH}_{3}\right)$, methyl formate $\left(\mathrm{CH}_{3} \mathrm{OCOH}\right)$, and formyl radical $(\mathrm{HCO})$. According to Cernicharo, $\mathrm{CH}_{3} \mathrm{O}$ is one of the key precursors of COMs. The formation of this radical, either in the ices or in the gas phase, could therefore be the first step to initiate the chemistry of COMs (Öberg et al. 2009; Antiñolo et al. 2016). In the gas phase, methoxy could be formed from the photodissociation of methanol or by the reaction of methanol with the radical $\mathrm{OH}$. To clarify the importance of methanol as a generating species, laboratory experiments using the CRESU technique have been performed (Antiñolo et al. 2016) to measure the reaction $\mathrm{CH}_{3} \mathrm{OH}+\mathrm{OH}$ at temperatures as low as $22 \mathrm{~K}$. These experiments have shown that the reaction rate increases considerably at low temperatures, with the methoxy $\mathrm{CH}_{3} \mathrm{O}^{\bullet}$ and hydroxymethyl $\mathrm{CH}_{2} \mathrm{OH}^{\bullet}$ radical as the most likely products. When methoxy is available in the gas phase, its radiative association with $\mathrm{CH}_{3}$ could produce dimethyl ether (Balucani et al. 2015), and its reaction with other species could lead to more complex species.

Highly energetic particles could have a significant effect on the chemistry of interstellar ices (Shingledecker \& Herbst 2018), especially in cold dense molecular cloud cores, where thermal energy is not sufficient to drive the normal diffusive chemistry of grain species (Ruaud et al. 2015). In order to provide theoretical support for the formation of COMs in ices through the reaction of methanol with other species, we have undertaken a systematic ab initio study of the system $\left(\mathrm{CH}_{3} \mathrm{OH}\right)_{10}$ ice-mantle plus $\mathrm{OH}^{-}, \mathrm{OH}$, and $\mathrm{OH}^{+}$. We here present the first part results of ab initio molecular dynamics (AIMD) simulations of the irradiation of an amorphous methanol-ice mantle that is impacted by $\mathrm{OH}^{-}$molecules. The results of $\mathrm{OH}$ radical and $\mathrm{OH}^{+}$cation will be published in a second article, in which we analyze the charge effect and COM formation processes as well. The $\mathrm{OH}$ radical, which is one of the most abundant molecules in the ISM, can easily form its anion by the $\mathrm{OH}+\mathrm{e}^{-} \rightarrow \mathrm{OH}^{-}+1.83 \mathrm{eV}$ process, leading to the stable anion $\mathrm{OH}^{-}$. Its rotational and vibrational spectrum has been measured in the laboratory (Liu \& Oka 1986; Owrutsky et al. 1985), but it has not been detected in space so far. Even if $\mathrm{OH}^{-}$has a low abundance in the ISM, it is detected in other astrophysical environments such as the coma of comets series (Chaizy et al. 1991). From the theoretical point of view, the $\mathrm{OH}^{-}$anion is extremely interesting because it is isoelectronic with $\mathrm{H}_{2} \mathrm{O}$ and is a closed-shell species. It can therefore be considered as a prototype for the interaction of the water molecule in interstellar and cometary ices (Cordiner \& Charnley 2014), and moreover, it can relatively easily be modeled by calculations based on first principles.

In our study of the reaction of methanol under the impact of $\mathrm{OH}^{-}$projectile, we use the Born-Oppenheimer ab initio molecular dynamics to identify which outcomes emerge depending on conditions such as the kinetic energy of the $\mathrm{OH}^{-}$projectile and the impact parameters of the collision. We also comment in detail on how the outcome could be linked to the formation of COMs. The remainder of this paper is organized as follows. In Sect. 2 (computational details) we describe the calculation model in more detail. The main outcomes of our simulations are presented in Sect. 3 and discussed in Sect. 4. We present our conclusions in Sect. 5.

\section{Computational details}

We simulated a methanol ice mantle as a cluster with ten units of methanol (hereafter $\left(\mathrm{CH}_{3} \mathrm{OH}\right)_{10}$-ice-mantle) in collision with $\mathrm{OH}^{-}$as a projectile. According to Boyd \& Boyd (2007), this cluster corresponds to the most stable isomer. We chose this cluster because its size is a good compromise between a good representation of a real dust ice mantle and the computational cost of the AIMD we used to simulate the impact of $\mathrm{OH}^{-}$. The collision was set to occur in the ground state of the species. This is a good approximation because the lowest excitation energy of methanol (at least $6 \mathrm{eV}$ ) (Varela et al. 2015) and hydroxyl (at least $4 \mathrm{eV}$ ) (Schofield \& Kjaergaard 2004) is a significant fraction of the kinetic energy of the projectile we used during the simulations (10 to $22 \mathrm{eV}$ ), which implies a low probability of nonadiabatic dynamics. Therefore, we used Born-Oppenheimer molecular dynamics (BOMD) at constant energy. This microcanonical ensemble approximation reproduces the conditions of the ISM because the low particle density inhibits the dissipation of thermal energy on timescales similar to the collision ( $<400 \mathrm{fs})$.

Forces on atoms and total energy were calculated using DFT within the Kohn-Sham (KS) formalism. The KS equations are a set of mono-electronic Schrödinger equations with a mean field for electrons that can recover the density of the actual interacting system. Although the KS equations are formally exact, in practice, only approximations to the exchangecorrelation potential of the mean-field are known. Here we used the long range-corrected hybrid functional of Head-Gordon et al., $\omega$ B97X-D (Helgaker et al. 1990; Uggerud \& Helgaker 1992; Bolton et al. 1998). KS orbitals were expanded in a basis set of Gaussian functions centered in each atom; namely, the Pople 6-31+G(d,p) basis set (Rassolov et al. 2001). This $\omega \mathrm{B} 97 \mathrm{X}-\mathrm{D}$ basis set is known to be flexible enough to describe reactive collisions (McBride et al. 2013). A Verlet-velocity algorithm with a time step of $0.5 \mathrm{fs}$ was used to integrate the equations of motion. This time step guarantees that the energy is conserved within a few hundreds of $\mathrm{kcal} \mathrm{mol}^{-1}$ during the whole simulation. All calculations were made using the electronic structure package Gaussian 09 (Frisch et al. 2009).

In all collisions the oxygen atom of $\mathrm{OH}^{-}$pointed to the center of mass of the $\left(\mathrm{CH}_{3} \mathrm{OH}\right)_{10}$-ice-mantle while the initial kinetic energy of the $\left(\mathrm{CH}_{3} \mathrm{OH}\right)_{10}$-ice-mantle was set to the equivalent of $30 \mathrm{~K}$ (Dawes et al. 2007). To find the range of energy of the projectile in which a rich chemistry occurs, we preliminary scanned impact energies from 5 to $40 \mathrm{eV}$. This range corresponds to an estimation of the limits of an elastic collision of the projectile with the cluster and an ultrafast penetration of the projectile with no time for reactions to occur (Kohanoff \& Artacho 2008).

Impacts below $10 \mathrm{eV}$ result in adsorption of $\mathrm{OH}^{-}$on the surface of the $\left(\mathrm{CH}_{3} \mathrm{OH}\right)_{10}$-ice-mantle, while impacts with kinetic energy above $22 \mathrm{eV}$ rapidly evaporate the mantle and breaking the methanol ice mantle structure. Consequently, we focused only on collisions with initial $\mathrm{OH}^{-}$kinetic energy of $10,12,15$, 18,20 , and $22 \mathrm{eV}$, where the richest chemistry takes place. For each impact energy, 24 trajectories with a total physical time of $400 \mathrm{fs}$ were simulated. These trajectories start with the velocity of $\mathrm{H}-\mathrm{O}$ axis of $\mathrm{OH}^{-}$projectile pointing toward the center of mass of the $\left(\mathrm{CH}_{3} \mathrm{OH}\right)_{10}$-ice-mantle. The 24 starting points were evenly distributed over a sphere, as depicted in Fig. 1, to obtain diversity in the impact factors. 


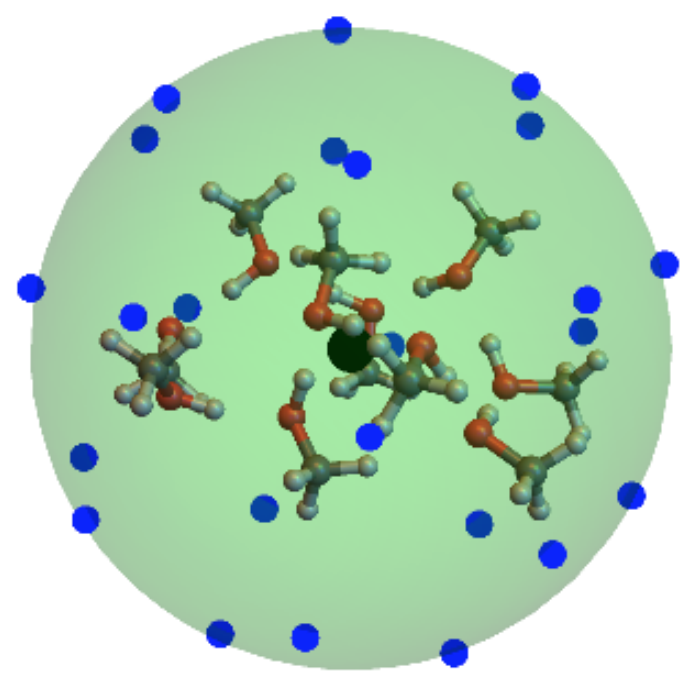

Fig. 1. Schematic representation of the initial conditions used for the molecular dynamics of the collision of $\mathrm{OH}^{-}$and a methanol ice-mantle. Each blue dot represents an initial position of the $\mathrm{OH}^{-}$projectile, whose $\mathrm{O}-\mathrm{H}$ axis points toward the center of mass of the methanol cluster (black circle) with its oxygen atom facing the cluster. The 24 points on the surface are evenly distributed such that the solid angle subtended by three closest-neighbor points on the surface and the center of the sphere is $\frac{\pi}{5} \mathrm{sr}$.

Each trajectory was visually inspected to search for wellformed intermediates or products. By well formed, we mean molecules that keep their structure for five or more times the period of the important vibrational mode involved in the reaction, that is, at least $60 \mathrm{fs}$. For instance, if an intermediate is formed through a hydrogen transfer to oxygen, then this newly formed bond should oscillate at least five times before the molecule follows its way along a new reaction path. Finally, when needed, the local population analysis of Mulliken (Mulliken 1955) was used to verify the charge of species involved in the reaction pathways. To simplify the nomenclature in Table 1 , we indicate $\mathrm{CH}_{3} \mathrm{OH}+\mathrm{OH}^{-} \rightarrow$ products instead of $\left(\mathrm{CH}_{3} \mathrm{OH}\right)_{10}+\mathrm{OH}^{-} \rightarrow$ products $+\left(\mathrm{CH}_{3} \mathrm{OH}\right)_{x}$.

\section{Results}

In the set of simulations using $\mathrm{OH}^{-}$as a projectile, different COMs are formed, such as methylene glycol $\left(\mathrm{CH}_{2}(\mathrm{OH})_{2}\right)$ and radicals such as $\mathrm{OCH}_{2} \mathrm{OH}^{\circ}$, which have not been detected in the ISM. Some of the other molecules produced here have already been detected in the ISM, for example, the methyl radical $\left(\mathrm{CH}_{3}{ }^{\circ}\right.$, methoxy radical $\mathrm{CH}_{3} \mathrm{O}^{\bullet}$ ) (Cernicharo et al. 2012), dimethyl ether $\left(\mathrm{CH}_{3} \mathrm{OCH}_{3}\right)\left(\right.$ Snyder et al. 1974), formaldehyde $\left(\mathrm{H}_{2} \mathrm{CO}\right)$ (Snyder et al. 1969), and formaldehyde protonated $\left(\mathrm{H}_{2} \mathrm{COH}^{+}\right)$ (Ohishi et al. 1996).

As mentioned above, we used projectile kinetic energy ranges from $10 \mathrm{eV}$ to $22 \mathrm{eV}$. Below $10 \mathrm{eV}$, the $\left(\mathrm{CH}_{3} \mathrm{OH}\right)_{10}$-icemantle only warms up, which reduces the number of hydrogen bonds, and deforms the structure, and ejects some methanol molecules into the gas phase (desorption). Above $22 \mathrm{eV}$, all molecules are ejected into the gas phase, which destroys the methanol ice mantle and breaks the $\mathrm{CH}_{3} \mathrm{OH}$ molecules.

Figure 2 shows a general overview of the BOMD results obtained between $\left(\mathrm{CH}_{3} \mathrm{OH}\right)_{10}$-ice-mantle and $\mathrm{OH}^{-}$projectile. We analyze the results of the formation and destruction processes observed in the simulations below at impact energies of
10 and $12 \mathrm{eV}$ in Sect. 3.1, followed by reactions at impact energies of 15 to $22 \mathrm{eV}$ in Sect. 3.1.

\subsection{Reactions at impact energies of 10 and $12 \mathrm{eV}$}

Impacts ${ }^{1}$ with projectile energy of $10 \mathrm{eV}$ always yield one main product that is listed as reaction (1) in Table 1. Figure 3 plots the potential energy as a function of time since impact in reaction (1). After $40 \mathrm{fs}$ since the collision, a potential energy barrier is observed that is associated with the formation of a methoxy $\mathrm{CH}_{3} \mathrm{O}^{-}$. After a time of $100 \mathrm{fs}$, no new chemical bonds are created or destroyed. Thus, only a primary process was observed.

The $\mathrm{OH}$-group in the $\left(\mathrm{CH}_{3} \mathrm{OH}\right)_{10}$-ice-mantle is not reactive because of the hydrogen bridges. Thus, it is not easy to extract a proton from it. After the impact with $\mathrm{OH}^{-}$, the substrate structure absorbs part of the kinetic energy to break the hydrogen bridges, which causes the hydroxyl group to react more easily. The breaking of these hydrogen bonds makes a hydroxyl available and tends to form $\mathrm{CH}_{3} \mathrm{O}^{\bullet}$ instead of $\mathrm{CH}_{2} \mathrm{OH}^{\bullet}$. This behavior is identical in all simulations at $10 \mathrm{eV}$.

Impacts with a kinetic energy of $12 \mathrm{eV}$ also most often lead to the formation of $\mathrm{CH}_{3} \mathrm{O}^{-}$through reaction (1). However, three additional chemical pathways (reactions (2)-(4)) can also occur (see Table 1).

The $\mathrm{CH}_{3}$. and $\mathrm{OH} \cdot$ species are formed in reaction (2) through direct impact of the hydroxyl ion on the $\mathrm{C}-\mathrm{O}$ bond in methanol. They can escape from the mantle with no further reactions.

Reaction (3) in Table 1 produces the formation of methylene glycol (or diol) $\mathrm{CH}_{2}(\mathrm{OH})_{2}$, which has not been detected in the ISM. At higher impact energies, this species can undergo a secondary process, the dehydration to produce formaldehyde $\left(\mathrm{H}_{2} \mathrm{CO}\right)$ and water; both are abundant in the ISM (Bacmann \& Faure 2016). This reaction requires the elimination of a proton via nucleophilic substitution $\left(S_{\mathrm{N} 2}\right.$ mechanism). The process takes about $50 \mathrm{fs}$.

Reaction (4) is a secondary process that starts after the products obtained from reaction (3) are stabilized. This mechanism exhibits the formation of $\mathrm{H}_{2}$. The BOMD simulation shows that the two hydrogen atoms hover over the grain surface until structural conditions are favorable for $\mathrm{H}_{2}$ association.

\subsection{Reactions at an impact energy of 15 to $22 \mathrm{eV}$}

When the kinetic energy of the projectile is $15 \mathrm{eV}$ or higher, many more reaction paths are possible. The reactions occur far from equilibrium; thus, the energy profile gives little information on reaction barriers. The outcomes of the reactions are listed in Table 1. The last column lists the impact energies in which the reactions were produced. The first four reactions are the same as in the $12 \mathrm{eV}$ kinetic energy case. The primary outcome between $15 \mathrm{eV}$ and $22 \mathrm{eV}$ is still $\mathrm{CH}_{3} \mathrm{O}^{-}$. The second most probable product formed is methylene glycol $\left(\mathrm{CH}_{2}(\mathrm{OH})_{2}\right)$ at energies between $15 \mathrm{eV}$ and $22 \mathrm{eV}$, as illustrated by reaction (3).

Using an impact energy of $15 \mathrm{eV}$ on the $\left(\mathrm{CH}_{3} \mathrm{OH}\right)_{10^{-}}$ ice-mantle corresponds to an average energy of $1.36 \mathrm{eV}$ per molecule in the system including the projectile. This energy is sufficient to produce a variety of reactions. We find 18 reaction pathways and report them in Table 1 . Reactions (1)-(4) are the same as were obtained with a $12 \mathrm{eV}$ projectile, but their formation time decreases because the impact energy is higher at $15 \mathrm{eV}$.

1 Figure 1 shows the impact configurations. 


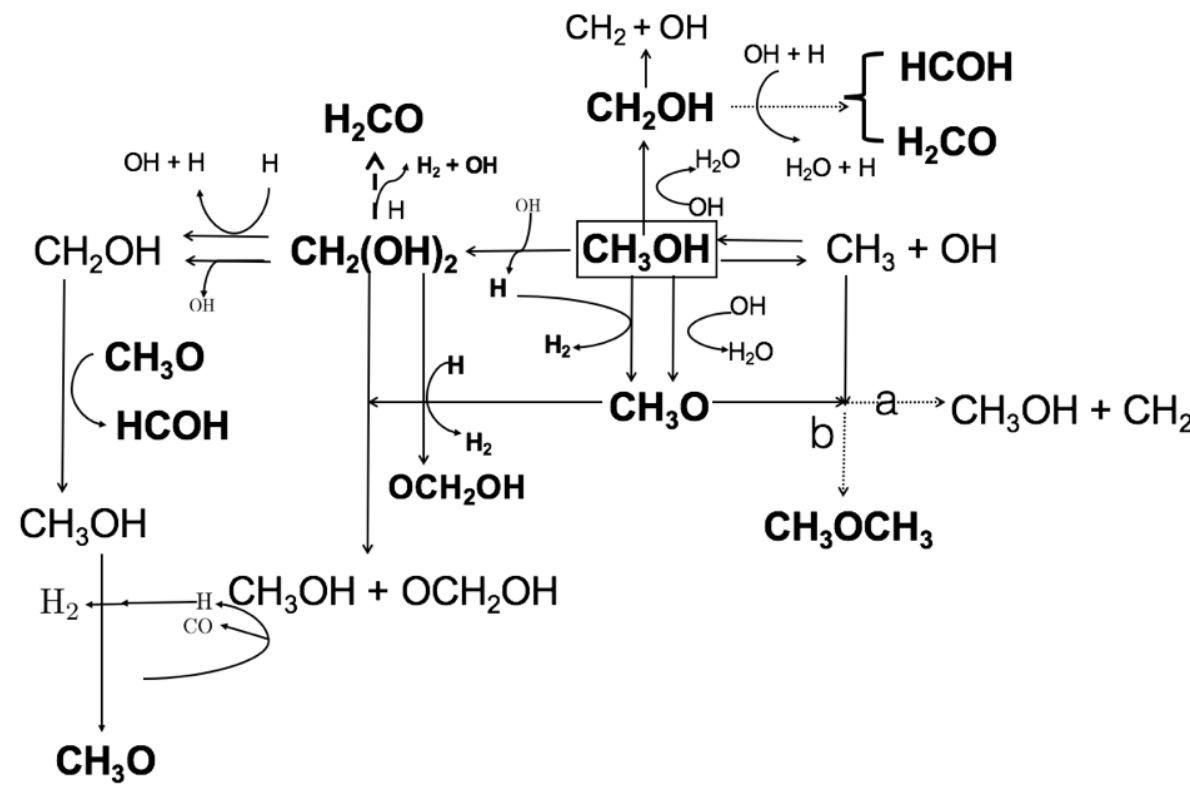

Fig. 2. Chemical network of COMs obtained after bombardment of the $\left(\mathrm{CH}_{3} \mathrm{OH}\right)_{10}$-icemantle with $\mathrm{OH}^{-}$using impact energies of 10 , $12,15,18,20$, and $22 \mathrm{eV}$. The $\left(\mathrm{CH}_{3} \mathrm{OH}\right)_{10}$-icemantle is represented as $\mathrm{CH}_{3} \mathrm{OH}$ hereafter, and radicals are not indicated by dots for clarity.

Table 1. Main products obtained from $\left(\mathrm{CH}_{3} \mathrm{OH}\right)_{10}$-ice-mantle in collision with a $\mathrm{OH}^{-}$projectile with kinetic energy of 10-22 eV.

\begin{tabular}{|c|c|c|c|c|}
\hline Number & Cher & ical & eaction & Impact energy $[\mathrm{eV}]$ \\
\hline 1 & $\mathrm{CH}_{3} \mathrm{OH}+\mathrm{OH}^{-}$ & $\rightarrow$ & $\mathrm{CH}_{3} \mathrm{O}^{-}+\mathrm{H}_{2} \mathrm{O}$ & $10,12,15,18,20,22$ \\
\hline 2 & $\mathrm{CH}_{3} \mathrm{OH}$ & $\rightleftarrows$ & $\mathrm{CH}_{3}{ }^{\circ}+\mathrm{OH}^{\bullet}$ & 12,15 \\
\hline 3 & $\mathrm{CH}_{3} \mathrm{OH}+\mathrm{OH}^{-}$ & $\rightarrow$ & $\mathrm{CH}_{2}(\mathrm{OH})_{2}+\mathrm{H}^{-}$ & $12,15,18,20,22$ \\
\hline 4 & $\mathrm{CH}_{3} \mathrm{OH}+\mathrm{H}^{-}$ & $\rightarrow$ & $\mathrm{H}_{2}+\mathrm{CH}_{3} \mathrm{O}^{-}$ & 12 \\
\hline 5 & $\mathrm{CH}_{2}(\mathrm{OH})_{2}$ & $\leftrightarrows$ & $\mathrm{CH}_{2} \mathrm{O}^{\bullet}+\mathrm{OH}^{\bullet}$ & 15,22 \\
\hline 6 & $\mathrm{CH}_{2}(\mathrm{OH})_{2}+\mathrm{CH}_{3} \mathrm{O}^{-}$ & $\rightarrow$ & $\mathrm{CH}_{3} \mathrm{OH}+\mathrm{OCH}_{2} \mathrm{OH}^{-}$ & 15 \\
\hline 7 & $\mathrm{CH}_{2}(\mathrm{OH})_{2}+\mathrm{H}^{-}$ & $\rightarrow$ & $\mathrm{H}_{2}+\mathrm{OCH}_{2} \mathrm{OH}^{-}$ & 15 \\
\hline 8 & $\mathrm{CH}_{3}{ }^{\circ}+\mathrm{CH}_{3} \mathrm{O}$ & $\leftrightarrows$ & $\mathrm{CH}_{3} \mathrm{OCH}_{3}$ & 15 \\
\hline 9 & $\mathrm{CH}_{3} \mathrm{OH}+\mathrm{OH}^{-}$ & $\rightarrow$ & $\mathrm{CH}_{2} \mathrm{OH}^{-}+\mathrm{H}_{2} \mathrm{O}$ & $15,20,22$ \\
\hline 10 & $\mathrm{CH}_{3} \mathrm{OH}+\mathrm{OH}^{-}$ & $\rightarrow$ & $\mathrm{CH}_{3}^{\bullet}+\mathrm{OH}^{\bullet}+\mathrm{OH}^{-}$ & 18,22 \\
\hline 11 & $\mathrm{CH}_{3} \mathrm{O}^{\bullet}+\mathrm{CH}_{3}^{\bullet}$ & $\rightarrow$ & $\mathrm{CH}_{3} \mathrm{OH}+\mathrm{CH}_{2}$ & 18 \\
\hline 12 & $\mathrm{CH}_{2}(\mathrm{OH})_{2}+\mathrm{H}^{-}$ & $\rightarrow$ & $\mathrm{CH}_{2} \mathrm{OH}^{\bullet}+\mathrm{OH}^{\bullet}+\mathrm{H}^{-}$ & 18,20 \\
\hline 13 & $\mathrm{CH}_{3} \mathrm{O}^{\bullet}+\mathrm{CH}_{2} \mathrm{OH}^{\bullet}$ & $\rightarrow$ & $\mathrm{CH}_{3} \mathrm{OH}+\mathrm{HCOH}$ & $18,20,22$ \\
\hline 14 & $\mathrm{CH}_{2}(\mathrm{OH})_{2}+\mathrm{H}$ & $\rightarrow$ & $\mathrm{HCOH}+\mathrm{H}_{2} \mathrm{O}$ & 18,20 \\
\hline 15 & $\mathrm{CH}_{2} \mathrm{OH}^{\bullet}+\mathrm{OH}^{\bullet}+\mathrm{H}$ & $\rightarrow$ & $\mathrm{H}_{2} \mathrm{CO}+\mathrm{H}_{2} \mathrm{O}+\mathrm{H}^{-}$ & $18,20,22$ \\
\hline 16 & $\mathrm{CH}_{2} \mathrm{OH}^{\bullet}+\mathrm{H}_{2} \mathrm{O}$ & $\rightarrow$ & $\mathrm{CH}_{2}{ }^{\bullet}+\mathrm{OH}^{-}+\mathrm{H}_{2} \mathrm{O}$ & 20,22 \\
\hline 17 & $\mathrm{CH}_{3} \mathrm{O}^{-}+\mathrm{HCOH}$ & $\rightarrow$ & $\mathrm{CH}_{3} \mathrm{OH}+\mathrm{CO}+\mathrm{H}_{2}$ & 20 \\
\hline
\end{tabular}

The hydroxymethyl radical $\mathrm{CH}_{2} \mathrm{OH}^{\bullet}$ was obtained with impacts energies of 18 and $20 \mathrm{eV}$ (reaction (12)). These products have a common origin: methylene glycol $\mathrm{CH}_{2}(\mathrm{OH})_{2}$. This precursor can also lead through a secondary process (reactions (6) and (7)) to a new product the $\mathrm{OCH}_{2} \mathrm{OH}^{-}$anion, which has not been identified in the ISM. In the first case (reaction (6)), the diol reacts with the methoxy $\mathrm{CH}_{3} \mathrm{O}^{-}$to yield $\mathrm{OCH}_{2} \mathrm{OH}^{-}$. In reaction (7), the diol reacts with $\mathrm{H}^{-}$to form $\mathrm{OCH}_{2} \mathrm{OH}^{-}+\mathrm{H}_{2}$.

Reaction (8) shows the formation of dimethyl ether $\mathrm{CH}_{3} \mathrm{OCH}_{3}$ after impacts of $15 \mathrm{eV}$. The mantle absorbs most of the kinetic energy as thermal energy. In this environment, the $\mathrm{CH}_{3} \mathrm{O}^{\bullet}$ and $\mathrm{CH}_{3}{ }^{\bullet}$ radicals are transient species with lifetimes between 45 and $164 \mathrm{fs}$. After this time, radicals trapped in the $\left(\mathrm{CH}_{3} \mathrm{OH}\right)_{10}$-ice-mantle diffuse and recombine to form $\mathrm{CH}_{3} \mathrm{OCH}_{3}+\mathrm{H}_{2} \mathrm{O}+\mathrm{OH}$, which are then ejected into the gas phase. Thus, secondary processes may contribute to the formation of COMs in astrophysical environments. At an impact energy of $18 \mathrm{eV}$, reaction (11) is favored instead.
The formation mechanism of $\mathrm{CH}_{3} \mathrm{OCH}_{3}$ can be divided into three steps:

(1) a homolytic rupture of $\mathrm{CH}_{3} \mathrm{OH}$ to produce $\mathrm{CH}_{3}{ }^{\bullet}+\mathrm{OH}^{\bullet}$;

(2) a proton abstraction from $\mathrm{CH}_{3} \mathrm{OH}$ to form water and a $\mathrm{CH}_{3} \mathrm{O}^{\bullet}$ radical;

(3) radical-radical reaction to produce $\mathrm{CH}_{3} \mathrm{OCH}_{3}$. These steps are illustrated in Fig. 4.

At an impact energy of $18 \mathrm{eV}$, we found the $\mathrm{HCOH}$ isomer of $\mathrm{H}_{2} \mathrm{CO}$. Its formation is a key factor of stabilization of its precursors $\mathrm{CH}_{3} \mathrm{O}^{\bullet}+\mathrm{CH}_{2} \mathrm{OH}^{\bullet}$ to form two stable chemical species: $\mathrm{CH}_{3} \mathrm{OH}$ and $\mathrm{HCOH}$ in a "chair" structure. The $\mathrm{HCOH}$ appears in reactions (13) and (14) (see Table 1) with impact energies of 18 to $22 \mathrm{eV}$. The formation mechanism for this molecule can be described in the following three steps:

(1) diol formation: $\mathrm{CH}_{2}(\mathrm{OH})_{2}+\mathrm{H}$;

(2) fragmentation: $\mathrm{CH}_{2}(\mathrm{OH})_{2} \rightarrow \mathrm{CH}_{2} \mathrm{OH}^{\bullet}+\mathrm{H}_{2} \mathrm{O}+\mathrm{CH}_{3}$;

(3) proton abstraction: $\mathrm{CH}_{2} \mathrm{OH}^{\bullet} \rightarrow \mathrm{HCOH}+\mathrm{H}_{2} \mathrm{O}+\mathrm{CH}_{3} \mathrm{OH}$.

Finally, formaldehyde $\mathrm{H}_{2} \mathrm{CO}$ was formed through a secondary process (reaction (15)) after impact energies of 18, 20, 


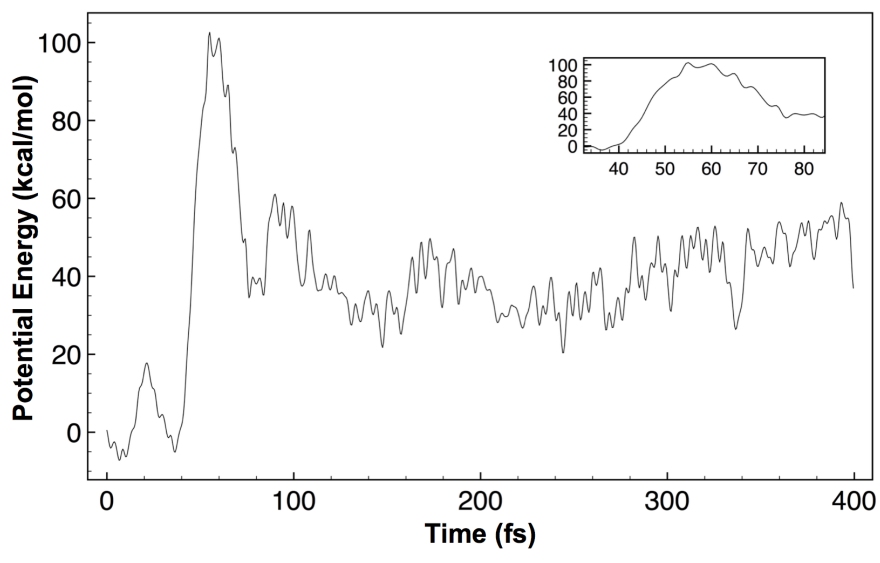

Fig. 3. Potential energy as a function of time since impact for all BOMD simulations with projectile at $10 \mathrm{eV}$. After a time of 100 fs no new chemical bonds are created or destroyed.

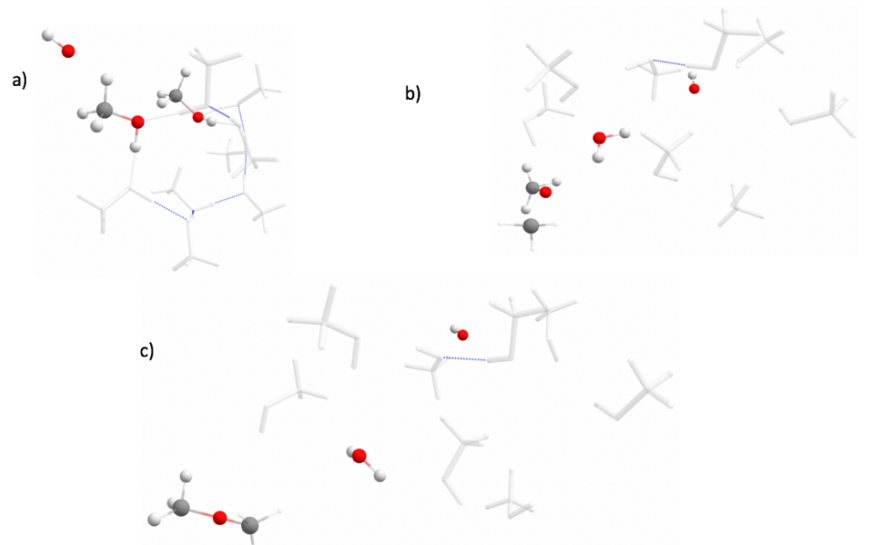

Fig. 4. Formation of dimethyl ether $\mathrm{CH}_{3} \mathrm{OCH}_{3}$ at $15 \mathrm{eV}$ following the chemical pathways as a function of time. $a$ : initial conditions. In color the projectile and methanol molecules that actively react. The remaning methanol molecules are represented by grey lines. They absorve some of the collision energy even though they do not break or form new chemical bonds. $b$ : radical formation at 87.5 fs. $c$ : radical-radical association at $164 \mathrm{fs}$. The colored $\mathrm{OH}$ and $\mathrm{H}_{2} \mathrm{O}$ molecules escape the system.

and $22 \mathrm{eV}$. The formation mechanism can be described in three steps:

(1) deprotonation of methyl-group;

(2) proton abstraction from the OH-group;

(3) stabilization through carbon-oxygen double bonds to form $\mathrm{H}_{2} \mathrm{CO}+\mathrm{H}_{2} \mathrm{O}+\mathrm{H}^{-}$.

\section{Discussion}

The simulation of reactive collisions of an energetic $\mathrm{OH}^{-}$projectile with an amorphous $\left(\mathrm{CH}_{3} \mathrm{OH}\right)_{10}$-ice mantle produces a rich diversity of COMS, including methoxy $\mathrm{CH}_{3} \mathrm{O}$, and hydroxymethyl $\mathrm{CH}_{2} \mathrm{OH}$ radicals and methylene glycol $\mathrm{CH}_{2}(\mathrm{OH})_{2}$ as primary products. The $\mathrm{CH}_{3} \mathrm{O}$ radical is the most frequent product at all energies, and the only product found at $10 \mathrm{eV}$. In this way, our results are in agreement with the gas-phase results reported by Shannon et al. (2013), which also led to the $\mathrm{CH}_{3} \mathrm{O}$ radical as the main product. If the reactants are correctly oriented, the reaction is expected to proceed by abstraction of a hydrogen atom at either the methyl or the hydroxyl site to produce $\mathrm{CH}_{3} \mathrm{O}$ or $\mathrm{CH}_{2} \mathrm{OH}$ radicals, respectively, which in most cases produces the $\mathrm{CH}_{3} \mathrm{O}$ radical over the $\mathrm{CH}_{2} \mathrm{OH}$ radical. Nevertheless, Antiñolo et al. (2016) pointed out that the role of grainsurface cannot be neglected in the formation of the $\mathrm{CH}_{2} \mathrm{OH}$ radical.

At collision energies higher than $10 \mathrm{eV}$, these COMs can participate in secondary reactions that generate more COMs. Thus, through these processes, relevant isomers such as methylene glycol and dimethyl ether are chemically methanol dependent.

Dimethyl ether $\mathrm{CH}_{3} \mathrm{OCH}_{3}$ has not been detected as a product of $\mathrm{CH}_{3} \mathrm{OH}$ ice reactions in previous experimental studies (Gerakines et al. 1996; Bennett et al. 2007; Baud \& Wouterloot 1980). However, in our simulations, $\mathrm{CH}_{3} \mathrm{OCH}_{3}$ is formed by secondary processes involving $\mathrm{CH}_{3}{ }^{\bullet}+\mathrm{CH}_{3} \mathrm{O}^{\bullet}$.

The diol $\mathrm{CH}_{2}(\mathrm{OH})_{2}$ forms by a one-step concerted mechanism through the addition of $\mathrm{OH}^{-}$and proton abstraction at impact energies above $15 \mathrm{eV}$. It is the second most frequent product observed.

Formaldehyde is created in a new chemical reaction route starting from methanol ice mantles. This can explain why the hydroxymethyl radical has not been detected in astronomical observations. We find that when the hydroxymethyl $\mathrm{CH}_{2} \mathrm{OH}^{\bullet}$ is formed, the radical will undergo proton abstraction to produce $\mathrm{H}_{2} \mathrm{CO}$.

These simulations provide new possible scenarios for the formation of COMs in interstellar environments. We showed that molecular projectiles with adequate kinetic energy impacting on cold ice-covered dust grains can produce rich COMs that are released into the gas phase. The required kinetic energies of $10-22 \mathrm{eV}$ are too high to be representative of typical conditions in molecular clouds, with typical gas kinetic temperatures of 8-20 K (Bergin \& Tafalla 2007). However, these projectiles can correctly represent conditions in localized regions such as photodissociation regions at the interface of HII regions and their parent molecular clouds, or in shocked regions due to the impact of high-velocity protostellar jets and outflows in the parent dense molecular cloud core. For example, specific locations in the protostellar outflow source L1157 are known to have a rich chemistry including abundant COMs (e.g., Bachiller et al. 2001; Arce et al. 2008). Similar processes are likely to be prevalent in regions of high-mass star formation, as shown recently by Guzmán et al. (2018). Guzmán et al. (2014) suggested that photodesorption may be an efficient mechanism to release complex molecules into the gas phase in photodissociation regions. We showed that moderate energy impacts with molecular projectiles can contribute not only to the desorption of COMS into the gas, but also be a significant factor in the creation of COMs themselves in ice mantles on dust grains.

\section{Conclusions}

Chemical reactions on icy grain mantles that subsequently eject products from the surface into the gas phase play a key role in the synthesis of COMs in astrophysical sources. We simulated the detailed interaction of an amorphous cold methanol decamer $\left(\left(\mathrm{CH}_{3} \mathrm{OH}\right)_{10}\right)$ bombarded by $\mathrm{OH}^{-}$projectiles with kinetic energies of $10-22 \mathrm{eV}$. We found that many complex organic molecules are produced in the collision, including $\mathrm{CH}_{3} \mathrm{O}^{-}, \mathrm{CH}_{2}(\mathrm{OH})_{2}, \mathrm{CH}_{2} \mathrm{O}^{\circ}, \mathrm{OCH}_{2} \mathrm{OH}, \mathrm{CH}_{3} \mathrm{OCH}_{3}, \mathrm{CH}_{2} \mathrm{OH}^{-}$, $\mathrm{HCOH}$, and $\mathrm{H}_{2} \mathrm{CO}$.

The reaction $\mathrm{CH}_{3} \mathrm{OH}+\mathrm{OH}^{-} \rightarrow \mathrm{CH}_{3} \mathrm{O}^{\bullet}+\mathrm{H}_{2} \mathrm{O}$ is most frequently observed in this work and thus the most probable to occur every time that methanol reacts with the hydroxyl anion. The projectile kinetic energy is crucial in breaking the hydrogen bridge and the subsequent modification of the ice-mantle 
structure. Different chemical products were observed as a function of the kinetic energy on impact. At high impact energies, the formation of $\mathrm{CH}_{2}(\mathrm{OH})_{2}$ was found to be more probable than $\mathrm{CH}_{3} \mathrm{O}^{\bullet}$. At higher impact energies, at least 17 reaction pathways are found, as listed in Table 1.

We confirmed that $\mathrm{H}_{2} \mathrm{CO}$ is a product of the reaction of methanol with a hydroxyl anion. This is consistent with the earlier suggestion of a chemical relation between the fragments of $\mathrm{CO}, \mathrm{HCO}, \mathrm{H}_{2} \mathrm{CO}, \mathrm{CH}_{3} \mathrm{O}^{\bullet}$, and $\mathrm{CH}_{3} \mathrm{OH}$ through an hydrogenation process (Bacmann \& Faure 2016, and references therein). Furthermore, we showed that methylene glycol $\mathrm{CH}_{2}(\mathrm{OH})_{2}$ is an outcome of primary process and that $\mathrm{HCOH}$ and $\mathrm{OCH}_{2} \mathrm{OH}$ are formed in secondary processes involving $\mathrm{CH}_{2}(\mathrm{OH})_{2}$. We find a new mechanism to produce $\mathrm{H}_{2} \mathrm{CO}$ every time $\mathrm{CH}_{2} \mathrm{OH}^{\bullet}$ is formed.

Given the projectile kinetic energies required for these reactions to occur, we suggest that these processes are likely relevant in the production of COMs in photodissociation regions and in shocks produced by high-velocity jets and outflows from young stellar objects.

Acknowledgements. This research was supported by FONDECYT-Chile grant 11140770 and CONICYT International Networks for young researchers Grant REDI170243. NI gratefully acknowledges support of Vicerectoría de Investigación y Postgrado (VRIP). DM acknowledges support from CONICYT project Basal AFB170002. CC and PF acknowledge support form Centers Of Excellence With Basal/Conicyt Financing, Grant FB0807 and FONDECYT-Chile grant 1181121, and 1180623. JG acknowledges support from Fondecyt postdoctoral fellowship 3170768. We thank Desmond MacLeod-Carey, Paola Caselli, Gil Jannes, and Christopher Shingledecker for their helpful comments and suggestions.

\section{References}

Antiñolo, M., Agúndez, M., Jiménez, E., et al. 2016, ApJ, 823, 25

Arce, H. G., Santiago-García, J., Jørgensen, J. K., Tafalla, M., \& Bachiller, R. 2008, ApJ, 681, L21

Bachiller, R., Pérez Gutiérrez, M., Kumar, M. S. N., \& Tafalla, M. 2001, A\&A, 372,899

Bacmann, A., \& Faure, A. 2016, A\&A, 587, A130

Bacmann, A., Taquet, V., Faure, A., Kahane, C., \& Ceccarelli, C. 2012, A\&A 541, L12

Balucani, N., Ceccarelli, C., \& Taquet, V. 2015, MNRAS, 449, L16

Baud, B., \& Wouterloot, J. G. A. 1980, A\&A, 90, 297

Bennett, C., Chen, S.-H., Sun, B.-J., Chang, A., \& Kaiser, R. 2007, ApJ, 660 1588

Bergin, E. A., \& Tafalla, M. 2007, ARA\&A, 45, 339
Bolton, K., Hase, W. L., \& Peslherbe, G. H. 1998, Modern Methods for Multidimensional Dynamics Computations in Chemistry (Singapore: World Scientific), 143

Boyd, S. L., \& Boyd, R. J. 2007, J. Chem. Theory Comput., 3, 54

Cernicharo, J., Marcelino, N., Roueff, E., et al. 2012, ApJ, 759, L43

Chaizy, P., Reme, H., Sauvaud, J., et al. 1991, Nature, 349, 393

Chang, Q., \& Herbst, E. 2016, ApJ, 819, 145

Cordiner, M. A., \& Charnley, S. B. 2014, Meteorit. Planet. Sci., 49, 21

Coutens, A., Rawlings, J., Viti, S., \& Williams, D. A. 2017, MNRAS, 467, 737

Dawes, A., Hunniford, A., Holtom, P. D., et al. 2007, Phys. Chem. Chem. Phys., 9, 2886

Ehrenfreund, P., \& Schutte, W. A. 2000, Adv. Space Res., 25, 2177

Frisch, M. J., Trucks, G. W., Schlegel, H. B., et al. 2009, Gaussian 09 Revision A.1 (Wallingford, CT: Gaussian Inc.)

Geppert, W. D., Hamberg, M., Thomas, R. D., et al. 2006, Faraday Discuss., 133, 177

Gerakines, P., Schutte, W., \& Ehrenfreund, P. 1996, A\&A, 312, 289

Gibb, E., Whittet, D., Boogert, A., \& Tielens, A. 2004, ApJS, 151, 35

Guzmán, V. V., Pety, J., Gratier, P., et al. 2014, Faraday Discuss., 168, 103

Guzmán, A. E., Guzmán, V. V., Garay, G., Bronfman, L., \& Hechenleitner, F. 2018, ApJS, 236, 45

Harada, N., Hasegawa, Y., Aikawa, Y., et al. 2017, ApJ, 837, 78

Helgaker, T., Uggerud, E., \& Jensen, H. J. A. 1990, Chem. Phys. Lett, 173, 145

Kohanoff, J., \& Artacho, E. 2008, AIP Conf. Proc., 1080, 78

Liu, D.-J., \& Oka, T. 1986, J. Chem. Phys., 84, 2426

McBride, E. J., Millar, T. J., \& Kohanoff, J. J. 2013, J. Phys. Chem. A, 117, 9666

Mulliken, R. S. 1955, J. Chem. Phys., 23, 1833

Öberg, K. I., Garrod, R. T., van Dishoeck, E. F., \& Linnartz, H. 2009, A\&A, 504, 891

Öberg, K. I., Bottinelli, S., Jørgensen, J. K., \& van Dishoeck, E. F. 2010, ApJ, 716,825

Ohishi, M., Ishikawa, S.-I., Amano, T., et al. 1996, ApJ, 471, L61

Owrutsky, J. C., Rosenbaum, N. H., Tack, L. M., \& Saykally, R. J. 1985, J. Chem. Phys., 83, 5338

Rassolov, V. A., Ratner, M. A., Pople, J. A., Redfern, P. C., \& Curtiss, L. A. 2001, J. Comput. Chem., 22, 976

Reboussin, L., Wakelam, V., Guilloteau, S., \& Hersant, F. 2014, MNRAS, 440, 3557

Ruaud, M., Loison, J. C., Hickson, K. M., et al. 2015, MNRAS, 447, 4004

Saito, T., Iono, D., Yun, M. S., et al. 2015, ApJ, 803, 60

Saito, T., Iono, D., Espada, D., et al. 2016, ApJ, 834, 6

Schofield, D. P., \& Kjaergaard, H. G. 2004, J. Chem. Phys., 120, 6930

Shannon, R. J., Blitz, M. A., Goddard, A., \& Heard, D. E. 2013, Nat. Chem., 5, 745

Shingledecker, C. N., \& Herbst, E. 2018, Phys. Chem. Chem. Phys., 20, 5359

Snyder, L. E., Buhl, D., Zuckerman, B., \& Palmer, P. 1969, Phys. Rev. Lett., 22, 679

Snyder, L., Buhl, D., Schwartz, P., et al. 1974, ApJ, 191, L79

Uggerud, E., \& Helgaker, T. 1992, J. Am. Chem. Soc., 114, 4265

Varela, K., Hargreaves, L. R., Ralphs, K., et al. 2015, J. Phys. B: At. Mol. Opt. Phys., 48, 115208

Vasyunin, A., \& Herbst, E. 2013, ApJ, 769, 34

Vasyunin, A. I., Caselli, P., Dulieu, F., \& Jiménez-Serra, I. 2017, ApJ, 842, 33

Zahorecz, S., Jimenez-Serra, I., Testi, L., et al. 2017, A\&A, 602, L3 